\title{
HOMOGENEIZAÇÃO DA PRECIPITAÇÃO PLUVIOMÉTRICA NA BACIA HIDROGRÁFICA DO RIO GOIANA - PE, COM MÉTODO DE ANÁLISE DE AGRUPAMENTO
}

\author{
Antonio Marcos dos Santos ${ }^{1}$; Josiclêda Domiciano Galvíncioº ${ }^{2}$ Magna Soelma Beserra de \\ Moura $^{3}$
}

Artigo recebido em 03/09/2008 e aceito em 15/10/2008.

\section{RESUMO}

O objetivo deste estudo é usar o método de análise de agrupamento de Ward para mapear a pluviosidade homogênea na bacia hidrográfica do rio Goiana-PE e posteriormente verificar os principais fatores físicos, internos a bacia, que influenciam na espacialização da chuva. Como medida de dissimilaridade foi empregada a distância euclidiana. Os resultados mostraram que a bacia hidrográfica do rio Goiana possui três regiões pluviometricamente homogêneas e que estão fortemente influenciadas pelos fatores marítimos (longitudinais) e topográficos. Busca-se com estes resultados ampliar a difusão deste método entre os trabalhos envolvendo a Geografia e as ciências afins e contribuir com posteriores diagnósticos que envolvam a dinâmica climática nesta bacia.

Palavras-chave: agrupamento de dados, preenchimentos de falhas e distribuição pluviométrica.

\section{HOMOGENISATION OF THE RAINFALL IN THE GOIANA - PE WATERSHED, WITH CLUSTER ANALYSIS}

\begin{abstract}
The objective of this study is it of using the method of cluster analysis of grouping of Ward for distribution the homogeneous rain in the basin watershed of the river Goiana-PE and later on to verify the main physical, internal factors the basin, that you/they influence in the espacialização of the rain. As dissimilarity measure was used the distance euclidiana. The results showed that the basin watershed of the river Goiana possesses three areas of homogeneous rains and that are strongly influenced by the marine factors (longitudinal) and topographical. It is looked for with these results to enlarge the diffusion of this method among the works involving the Geography and the kindred sciences and to contribute with posterior diagnoses that involve the climatic dynamics in this basin.
\end{abstract}

keywords: grouping of the positions of rains, to fill of flaws and distribution of the rains.

\footnotetext{
${ }^{1}$ Mestrando em Geografia pela Universidade Federal de Pernambuco - e-mail: geo_fisica@yahoo.com.br; Avenida Professor Morais Rego, s/n.

Cidade Universitária, Recife-PE

${ }^{2}$ Professora do Departamento de Geografia da Universidade Federal de Pernambuco. E-mail: josicleda@hotmail.com

${ }^{3}$ Pesquisadora da Embrapa Semi-Árido - e-mail: magna@cpatsa.embrapa.br

Santos, A. M. dos; Galvíncio, J. D. Moura, M S. B. de. 


\section{RBGF - Revista Brasileira de Geografia Física}

Recife-PE Vol. 01 n.01 Mai/Ago 2008, 14-27

\section{INTRODUÇÃO}

Entre os inúmeros elementos climáticos, a pluviosidade se destaca por apresentar uma excelente interação com os outros elementos climáticos. Também interage com os aspectos topográficos, pedológicos, fitogeográficos participando significativamente da modelagem dos Geossistemas terrestres. Ou seja, a pluviosidade como um elemento climático, funciona como insumo energético básico aos Geossistemas (MONTEIRO, 2001). Nesta perspectiva, torna-se imprescindíveis diagnósticos que venham analisar a distribuição da pluviosidade numa bacia hidrográfica.

Melo Neto (2007a) destaca que nos últimos anos vem crescendo o número e a diversidade de estudos abordando a interrelação entre o clima e as bacias hidrográficas, tendo como componente principal o papel da pluviosidade. Porém, um dos problemas encontrados para realização de trabalhos direcionados a esta temática é a falha (falta) de dados contínuos nas estações pluviométricas a serem analisadas.

Dias (2007) destaca que muitas vezes após a análise dos dados pluviométricos coletados em uma bacia hidrográfica restam poucos que não possuem falhas, os quais, são insuficientes para cobrir toda a área de estudo comprometendo a realização de um diagnóstico acurado para o entendimento do processo hidrológico. Para suprir esta lacuna, técnicas estatísticas vêm sendo aplicadas em estudos no Brasil e em outros países.

Em pesquisa realizada no Estado de Minas Gerais, Torres (2007) destaca que a homogeneização das informações pluviométricas através da análise de agrupamento voltada para regionalização destes dados é uma das mais bem sucedida aplicação estatística para suprir faltas de dados pluviométricos em uma bacia hidrográfica. Idéia compartilhada por Tucci (1993) o qual, enfatiza que através da regionalização hidrológica empregando métodos estáticos, é possível chegar a grupos homogêneos com semelhança na resposta hidrológica de cada região. Ainda para este autor, a regionalização é utilizada para identificar áreas que apresentem um comportamento semelhante e, assim, respostas hidrológicas podem ser correlacionadas, facilitando, desta maneira, a transposição de informações entre regiões.

O que favorece a correção de falhas de observações existentes.

Melo Neto (2007a) ao analisar os processos que vem contribuindo para erosão de solos em uma das vertentes do Rio Jaguaribe no município de Conceição do Almeida no Estado da Bahia, regionalizou os dados pluviométricos de sete estações 


\section{RBGF - Revista Brasileira de Geografia Física \\ Recife-PE Vol. 01 n.01 Mai/Ago 2008, 14-27}

meteorológicas para obter futuramente em suas análises informações que pudessem ser transpostas para os postos com dados incompletos. Para alcançar seu objetivo foi empregada uma série de técnicas estatísticas, destacando a análise de agrupamento de Ward.

Em outro estudo divulgado, Melo Neto (2007b) utilizou a regionalização pluviométrica para analisar os principais fatores físicos que influenciam as diferentes quantidades de chuvas que atingiu sua área de estudo no período de 1970 a 2006. Este procedimento, segundo o autor, foi importante para diagnosticar o papel do relevo na distribuição pluviométrica.

Filho et al. (2005) empregando a análise de agrupamento (cluster analysis) identificaram no território brasileiro 25 zonas (regiões) homogêneas quanto a distribuição da probabilidade de chuva. Seu trabalho foi desenvolvido com o objetivo de dar suporte a futuros estudos direcionados aos riscos climáticos na organização do espaço agrário nacional, principalmente em áreas com regulares dados de chuva. $\mathrm{Na}$ realização deste diagnóstico se empregou também o método de agrupamento para regionalização dos dados pluviométricos.

Neto e Villa Gois (2007) também empregam a análise de agrupamento para identificar regiões onde a pluviometria é semelhante entre si, ou seja, homogêneas na bacia hidrográfica do rio Da Dona. Seu objetivo com as regiões homogêneas é o de verificar o papel da topografia na distribuição das chuvas nesta bacia e a partir daí, diagnosticar os impactos ambientais provocados pelos sedimentos carregados pelas chuvas para as barragens construídas na referida bacia hidrográfica

Outro estudo de destaque envolvendo a temática discutida foi realizado no Estado de Táchira, território nacional da Venezuela por Lyra et al. (2006). Neste trabalho aplicou-se o método de Ward no agrupamento dos meses com pluviosidade mensal semelhante e também no das localidades com pluviosidade similar, formando assim as regiões homogêneas.

Com base nos estudos citados acima, nota-se a viabilidade e a variabilidade da aplicação escalar e territorial de métodos estatísticos principalmente a análise de agrupamento na regionalização de dados pluviométricos para diversas finalidades. Nesta perspectiva, o presente trabalho tem como objetivo identificar as regiões pluviometricamente homogêneas na bacia hidrográfica do rio Goiana, através da análise estatística de agrupamento. Utilizouse o método hierárquico de aglomeração de Ward, tendo como medida de dissimilaridade a distância euclidiana.

A partir dos resultados obtidos, foi realizada, complementarmente, uma investigação na busca de identificar os principais fatores físicos (interno a bacia) 


\section{RBGF - Revista Brasileira de Geografia Física \\ Recife-PE Vol. 01 n.01 Mai/Ago 2008, 14-27}

que contribuem na homogeneização dos dados pluviométricos.

O presente trabalho além de fornecer subsídios para o preenchimento de falhas nos dados pluviométricos da bacia estudada, assim como, contribuir na formação de um arcabouço metodológico para estudos em outras bacias hidrográficas que venham a enfrentar problemas semelhantes.

Busca-se também contribuir com a inter-relação entre os métodos e técnicas estatísticas com a ciência geográfica, reforçando a importância desta união para subsidiar estudos envolvendo a Geografia e as ciências afins que compartilham com a temática aqui discutida.

\section{MATERIAIS E MÉTODOS}

\section{Área de estudo}

A bacia hidrográfica do rio Goiana está localizada entre as coordenadas de 07²2’20” e 0754'47” de Latitude Sul e $34^{\circ} 49^{\prime} 06^{\prime \prime}$ e $35^{\circ} 41^{\prime} 43^{\prime \prime}$ de Longitude Oeste no Estado de Pernambuco (Figura 01). Possui uma área de 2.847,53 $\mathrm{Km}^{2}$ abrangendo 26 municípios sendo que apenas nove estão totalmente inseridos na bacia. Seu rio principal é formado pela confluência das sub-bacias do rio Capibaribe-Mirim com a do rio Tracunhaém.

Quanto às características físicas, a bacia hidrográfica apresenta quatro dos principais compartimentos regionais de relevo do Estado de Pernambuco segundo Jatobá (2006): são as Planícies Costeiras: os Tabuleiros Costeiros: as Colinas da Zona da Mata e porção do Planalto da Borborema a oeste.

A tipologia climática nesta bacia hidrográfica é representada pelo clima úmido a subúmido e seco a subúmido levando em consideração a classificação climática desenvolvida por Thornthwaite em 1955 apud Lacerda et al. (2006a). A temperatura média do ar varia de $24-25^{\circ} \mathrm{C}$ na maior parte da bacia e $23-24^{\circ} \mathrm{C}$ em uma pequena área a oeste sobre influencia da elevada altitude (LACERDA, et al., 2006b).

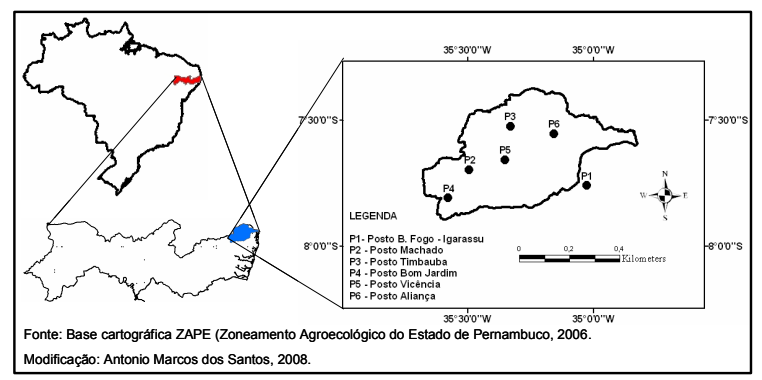

Figura 01: Mapa de localização dos postos pluviométricos na bacia hidrográfica do rio Goiana.

Foram obtidos provenientes da Superintendência do Desenvolvimento do Nordeste (SUDENE, 2008), dados de 27 postos pluviométricos. Porém, somente seis foram utilizados (Figura 01). Os demais, 21 no total, devido às falhas: como séries curtas e/ou descontinuas, foram descartados. A série histórica analisada compreende os anos de 1965, 1966, 1969, 1970, 1971, 1972, 


\section{RBGF - Revista Brasileira de Geografia Física \\ Recife-PE Vol. 01 n.01 Mai/Ago 2008, 14-27}

1974, 1975, 1976, 1978, 1979, 1980, 1981, 1982, 1983, 1984, 1985, 1986 e 1988.

As Tabelas 01, 02, 03, 04, 05 e 06 (anexo) apresentam uma síntese dos dados pluviométricos utilizados nesta análise. São mostrados os totais de chuva para cada ano da série histórica e a média geral para cada posto de coleta.

Selecionados os dados, gerou-se o agrupamento dos postos pluviométricos que possuem os regimes de chuva semelhantes entre si utilizando os totais mensais para cada ano. Para chegar até este resultado empregou-se o método hierárquico de agrupamento de Ward com a distância euclidiana que pode ser rodado através dos softwares Statistical Package for Social Sciences (SPSS), Statistical entre outros.

O papel central da análise hierárquica de agrupamento é identificar os elementos que se assemelham entre as variáveis dispostas (CARVALHO et al., 2006). Para isto a similaridade entre os dados de chuva dos postos pluviométricos foi medida através da distância euclidiana, expressa na equação 1 .

$$
D_{i, j}=\left|\sum_{k=1}^{n}\left(x_{k i}-x_{k 1}\right)\right|
$$

Onde Di,j é a distância euclidiana entre os postos (i primeiro posto e $\mathrm{j}$ o último posto), $\mathrm{n}$ corresponde ao número de postos, $\mathrm{X}_{\mathrm{ki}}$ representa o valor do posto i, é $\mathrm{XKj}_{\mathrm{K}}$ representa o valor da variável para o posto $\mathrm{j}$, e a soma acontece para todas as variáveis $\mathrm{X}$ consideradas.

Após medida a similaridade o próximo passo foi agrupar as variáveis, ou seja, os postos pluviométricos em regiões homogêneas, procedimento aplicado com a mesma finalidade em trabalhos realizado por Filho et al. (2005) e Melo Neto (2007 b). Para isto, empregou-se o método de Ward o qual avaliou os postos pelo seu grau de dispersão intragrupos, a qual é medida pela soma dos desvios quadráticos (SDQ) entre seus elementos. Formula corresponde a equação 2 .

$$
\mathrm{SQD}=\sum_{\mathrm{i}=1}^{\mathrm{q}}\left[\mathrm{d}\left(\mathrm{e}_{\mathrm{i}}, \mathrm{o}\right)\right]^{2},
$$

Onde d é o grau de dispersão dos postos, i representa o número total de agrupamento, é O representa o centróide, ou seja, a média de cada grupo formado.

A regionalização proposta deu-se com a proposição de dois cenários com base na análise do gráfico da inércia e do dendograma. Estes cenários referem-se cada um a quantidade de regiões possíveis, o primeiro com quatro e o segundo com três regiões. Para escolha do cenário que mais se aproxima da realidade dos dados, foi calculada a média anual aritmética da pluviosidade de cada região, formula matemática apresentada na equação 3 . 


$$
\bar{X}=\frac{1}{J} \sum_{J} X_{i j}
$$

Em que $\mathrm{X}_{\mathrm{ij}}$ é a pluviosidade total anual da região $i$ durante $j$ anos; $J$ é o número de anos no período escolhido (1965 a 1988) e I o número de postos em cada região (dados disponíveis nas Tabelas 01, 02, 03, 04, 05 e 06 (anexo).

De posse da regionalização pluviométrica, foi realizada a análise dos principais fatores físicos (internos a bacia) que influenciam na distribuição das chuvas. Para o proposto diagnóstico foi elaborado um mapa hipsométrico e efetuado a discussão em torno do papel da topografia e da longitude (proximidade com o litoral).

Foram utilizados os softwares IDRISI ANDES 15.0 e o ENVI 4.5 todos disponíveis no Laboratório de Geografia Física Aplicada da Universidade Federal de Pernambuco.

\section{RESULTADOS E DISCUSSÕES}

A inércia oferece duas opções para escolha do número de regiões homogêneas (Figura 02). Com base na disposição entre a distância euclidiana (eixo Y) e as variáveis (eixo X), observa-se que a maior distância ocorre entre a variável de número três com a de número quatro. Isto significa que há possibilidade de regionalizar os dados pluviométricos da bacia hidrográfica do rio
Goiana em três ou quatro regiões homogêneas.

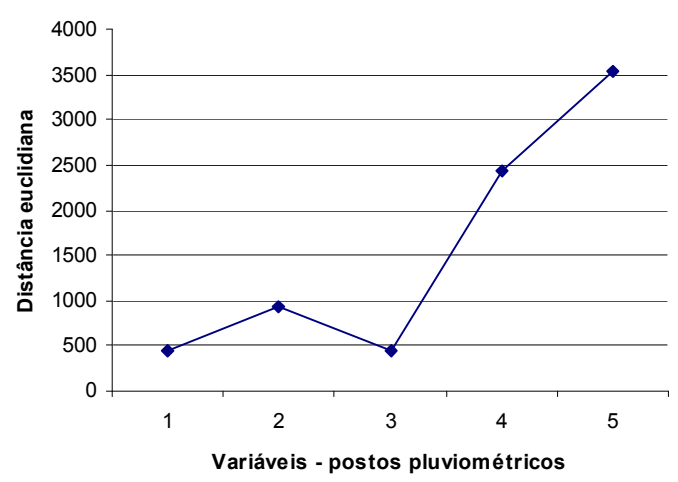

Figura 02: Gráfico de inércia entre as variáveis (postos pluviométricos) e a distância euclidiana.

Para escolha da quantidade das regiões pluviométricas foram construídos dois cenários onde se comparou o comportamento das médias anuais pluviométricas entre eles. $\mathrm{O}$ primeiro cenário configurou-se em quatro regiões e o segundo com três (Figura 03 em anexo).

Analisando o dendograma (Figura 03 em anexo), a partir da distância euclidiana de zero até 25 são formados vários grupos ou regiões homogêneas, as quais variam entre quatro grupos na distância cinco a um único grupo a partir da distância 25. Esta variabilidade de opções ocorre devido ao método de Ward formar grupos, minimizando a dissimilaridade.

O primeiro corte efetuado para o cenário um foi introduzido na distância cinco. Neste limite, têm-se quatro regiões homogêneas composta pela: Região I: Bota Fogo - Igarassu, Machados e Timbauba; 


\section{RBGF - Revista Brasileira de Geografia Física \\ Recife-PE Vol. 01 n.01 Mai/Ago 2008, 14-27}

Região II: Bom Jardim; Região III: Vicência e a Região IV: Aliança.

$\mathrm{O}$ segundo corte executado para o cenário dois, foi realizado na distância dez, obtendo-se três regiões pluviometricamente homogêneas, a Região I: Bota Fogo Igarassu, Machados e Timbauba; a Região II: Bom Jardim e Vicência e a Região III: Aliança.

Para o primeiro cenário, o calculo das médias pluviométricas das quatro regiões são apresentados na Figura 04. A Região I apresenta uma média pluviométrica superior a $1300 \mathrm{~mm}$. As demais regiões apresentam valores variando entre $1050 \mathrm{~mm}$ a $1253 \mathrm{~mm}$.

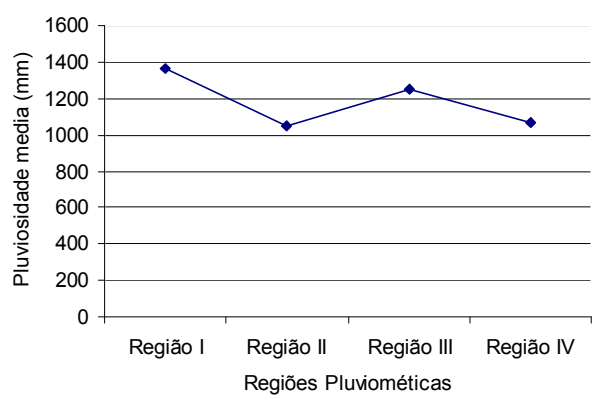

Figura 04: Pluviosidade média anual dos municípios regionalizados para o primeiro cenário.

Este cenário apresenta o comportamento linear entre as médias da pluviosidade das Regiões II e IV. Isto significa que estas duas Regiões podem formar um único grupo. Propósito que vai de encontro ao corte para o cenário um no dendograma, o qual prediz a formação de quatro regiões e não três como mostram a Figura 04.

Para o segundo cenário, o resultado da média pluviométrica das três regiões é apresentado na Figura 05. A Região I permanece com o mesmo valor apresentado no primeiro cenário. Já a Região II passa a ser formada por dois postos pluviométricos totalizando uma média de $1152 \mathrm{~mm}$. A Região III, a qual no primeiro cenário seria a quarta, permanece com a média no valor de $1067 \mathrm{~mm}$

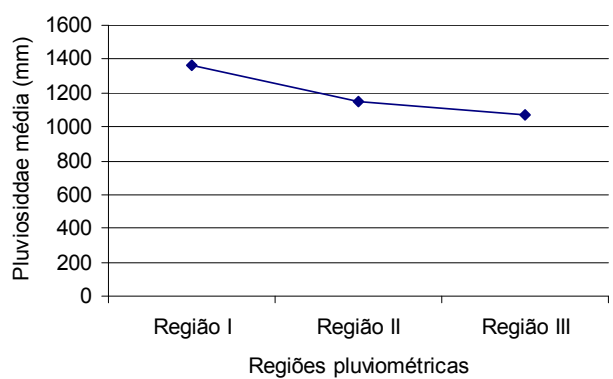

Figura 05: Pluviosidade média anual dos municípios regionalizados no segundo cenário.

Nesta perspectiva, no cenário dois os postos pluviométricos de Bota Fogo/Igarassu, Machados e Timbauba apresentam semelhanças no volume pluviométrico na série analisada. Em um segundo grupo, encontra-se os postos de Vicência e de Bom Jardim e por último o posto de Aliança.

A Figura 06 apresenta as regiões pluviometricamente homogêneas na bacia hidrográfica do rio Goiana. Nele é possível observar que a Região homogênea I é representada por postos distribuídos na 
porção leste e oeste da bacia. Já os postos representando a Região II estão presentes a sudoeste e a oeste. Ao norte está o único posto da Região III.

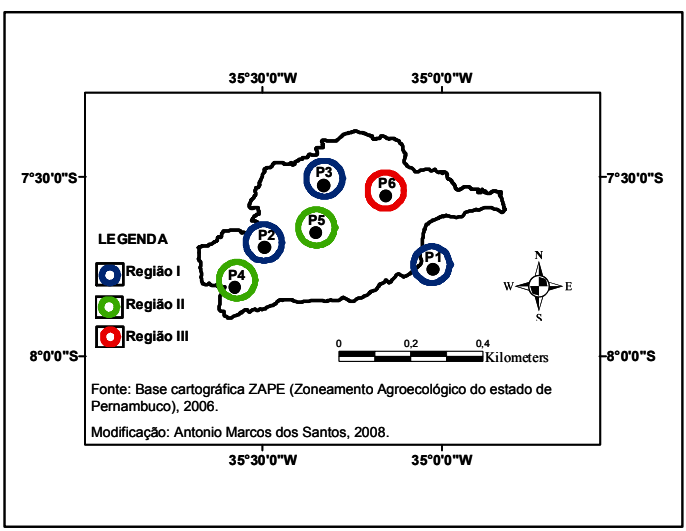

Figura 06: Mapa de regionalização da pluviosidade na bacia hidrográfica do rio Goiana.

Esta organização visual pode ser explicada por uma série de fatores que influenciam na distribuição pluviométrica. Nimer (1979) destaca que a Região Nordeste do Brasil é o ponto final de quatro sistemas de circulação atmosférica. Os quatros sistemas são: o sistema de norte, representado pela Convergência Intertropical; o sistema de sul, representado pelas Frentes Polares do Atlântico Sul; o sistema de oeste, representado por linhas de instabilidades tropicais e o sistema de leste, representado pelas ondas de lestes. Destes sistemas o que atinge com bastante significância a maior parte da bacia hidrográfica do rio Goiana são as ondas de lestes.

O avanço pela costa brasileira da Frente Polar Atlântica (sistema de sul) e seu encontro com os tépidos, duráveis e estáveis alísios de leste e sudeste do anticiclone do Atlântico Sul (sistema de leste), presente durante todo o ano no litoral oriental do Nordeste, provocam chuvas locais variando de outono a inverno (abril-agosto) (CAMPOS, 2003).

A medida que estes sistemas perdem força ao avançarem no sentido leste-oeste, conseqüentemente decresce os valores quantitativos de chuva que cai sobre a bacia hidrográfica no mesmo sentido (NIMER, 1969). Esta tendência pode ser comprovada ao comparar o posto P1 inserido na Região pluviométrica I com o posto P6 representante da Região pluviométrica III. O primeiro próximo ao litoral apresenta uma média anual pluviométrica no valor de 1536 $\mathrm{mm}$ enquanto o segundo logitudinalmente mais afastado do litoral apresenta uma média de $1067 \mathrm{~mm}$.

Os demais postos localizados a uma distância longitudinal maior em relação ao litoral, deveriam apresentar médias pluviométricas significativamente inferiores em comparação aos postos P1 e principalmente ao P6, levando em consideração o posicionamento de Nimer (1969). Porém, isto não ocorre. Exemplos dos postos $\mathrm{P} 2$ e $\mathrm{P} 3$, os quais possuem uma média pluviométrica no valor de $1266 \mathrm{~mm}$ e $1295 \mathrm{~mm}$, respectivamente. Se a proximidade com o litoral do posto $\mathrm{P} 1$ influencia o valor elevado da média 


\section{RBGF - Revista Brasileira de Geografia Fúsica \\ Recife-PE Vol. 01 n.01 Mai/Ago 2008, 14-27}

pluviométrica, os valores elevados obtidos para os postos P2 e P3 ocorrem provavelmente devido à influência da topografia.

A Figura 07 apresenta a hipsometria em metros da bacia hidrográfica do rio Goiana. Nela, os postos P2 e P3 estão localizados em uma área onde a altitude varia entre $274 \mathrm{~m}$ a $533 \mathrm{~m}$. Topograficamente, eles estão inseridos na encosta de várias serras e serrotes que atuam como divisores de água entre a bacia hidrográfica em estudo com outras bacias localizadas no Estado da Paraíba.

Bertoni e Tucci (2003) destacam que quando ventos úmidos e quentes soprando do litoral para o continente, encontram uma barreira montanhosa, elevam-se e resfriam adiabaticamente havendo condensação do vapor de água, formação de nuvens e ocorrência de precipitação pluviométrica. São as denominadas chuvas orográficas e responsáveis pela inserção dos postos $\mathrm{P} 2$ e P3 na Região pluviométrica I.

$\mathrm{Na}$ bacia hidrográfica do rio Goiana as chuvas são influenciadas pelo fator altitude, porém, de grande duração e suficiente para atuar na caracterização pluviométrica da região ao lado dos sistemas meteorológicos atuantes. Resultado semelhante foi encontrado por Melo Neto (2007a) para a bacia hidrográfica do rio Jaguaribe.

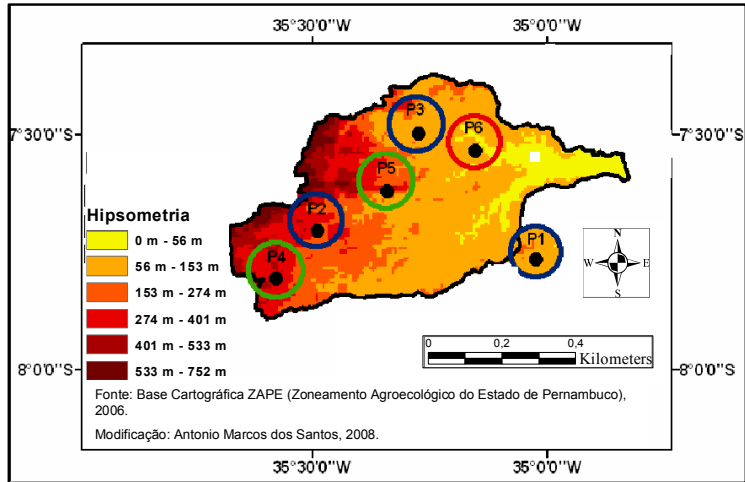

Figura 07: Mapa hipsométrico da bacia hidrográfica do rio Goiana-PE.

A topografia também influencia os registros pluviométricos nos postos da Região II principalmente no posto P5 localizado a frente de um conjunto de elevações de aproximadamente $300 \mathrm{~m}$ representada pelas Serras do Mascarenhas. As chuvas provocadas por esta barreira orográfica refletem significativamente na média pluviométrica calculada que chegou a 1253 mm. Já no posto P4 este valor cai, porém, mantém a influencia topográfica marcada pela encosta setentrional do Planalto da Borborema.

\section{CONCLUSÕES}

A bacia hidrográfica do rio Goiana possui três regiões pluviometricamente homogêneas, segundo a análise de agrupamento de Ward. Esta regionalização está interligada aos fatores longitudinais e principalmente topográficos.

Em relação aos resultados obtidos pela análise de agrupamento hierárquica empregando o método de ward, comprovou- 


\section{RBGF - Revista Brasileira de Geografia Física \\ Recife-PE Vol. 01 n.01 Mai/Ago 2008, 14-27}

se que é um mecanismo eficaz para regionalização dos dados referentes à pluviosidade em uma bacia hidrográfica.

Os postos pluviométricos de Bota Fogo/Igarassu, Machados e Timbaúba apresentam semelhanças na pluviometria e poderão ser utilizados para preenchimento de falhas reciprocamente. Os postos de Vicência e de Bom Jardim também seguem as mesmas semelhanças pluviométricas e reciprocidade no preenchimento de falhas.

\section{AGRADECIMENTOS}

Os autores agradecem a FACEPE Fundação de Amparo à Ciência e Tecnologia do Estado de Pernambuco pela concessão da bolsa e ao CNPq pelo auxílio financeiro através do Edital Universal 2007.

\section{REFERÊNCIAS}

BERTONI, J. C. \& TUCCI, C. E. M. Precipitação. In: TUCCI, C. E. M., ed. Hidrologia: ciência e aplicação. 2ed. Porto Alegre: EDUFRGS:ABRH, 2000. p.177241.

CAMPOS, H. L. Processo histórico de gestão na bacia hidrográfica do rio Beberibe - PE: uma retrospectiva. Tese de Doutorado. Centro de Ciências Matemáticas e da Natureza - Instituto de Geociências Programa de Pós-Graduação em Geografia.
Universidade Federal do Rio de Janeiro: Rio de Janeiro, 2003. 234 p.

CARVALHO, D. F.; SANTANA, A. C. de; MENDES, F. A. T.; Análise de cluster da indústria de móveis de madeira do Pará. $\mathbf{N}$.

Cad. NAEA, 9: 24-54, 2006.

DIAS, C. N. Regionalização pluviométrica em bacias hidrográficas. In: SIMPÓSIO BRASILEIRO DE GEOGRAFIA FÍSICA APLICADA, 12., 2007. Anais. Natal, UFRN, 2007. CD-ROM.

FILHO, T. F., ASSAD, E. C. \& LIMA, P. R. S.de R. e. Regiões pluviometricamente homogêneas no Brasil. R. Pesq. Agropec. Bras., 40: 311-322, 2005.

JATOBÁ, M. Compartimentos regionais do relevo. In: Atlas de bacias hidrográficas de Pernambuco. Recife: Secretaria de Ciência, Tecnologia e Meio Ambiente do Estado de Pernambuco, 2006. p.14-15.

LACERDA, F. FERREIRA, M. A. F. SOUZA, W. M. DA. Climas do Estado de Pernambuco. In: Atlas de bacias hidrográficas de Pernambuco. Recife: Secretaria de Ciência, Tecnologia e Meio Ambiente do Estado de Pernambuco, 2006(a). p.16-17. 


\section{RBGF - Revista Brasileira de Geografia Física}

Recife-PE Vol. 01 n.01 Mai/Ago 2008, 14-27

LACERDA, F. FERREIRA, M. A. F. no Brasil e alterações climáticas.:

SOUZA, W. M. DA. Temperaturas do ar médias anuais. In: Atlas de bacias hidrográficas de Pernambuco. Recife: Secretaria de Ciência, Tecnologia e Meio Ambiente do Estado de Pernambuco, 2006(b). p.16-17.

LYRA, G. B., GARCIA, B. I. L., STEFANO, S. M. de P., SEDIYAMA, G.C. \& SENTELHAS, P. C. Regiões homogêneas e funções de distribuição de probabilidade da precipitação pluvial no Estado de Táchira, Venezuela. R. Pesq. Agropec. Bras., Brasília, 41:205-215, 2006.

MELO NETO, M. S. de. Erosão dos solos nas encostas da bacia hidrográfica do rio Jaguaribe - Conceição do Almeida - Bahia. In: CONGRESSO DE PESQUISADORES DO RECÔNCAVO SUL DA BAHIA, 1., 2007. Anais. Amargosa, UFRB, 2007(a). p.134-135.

MELO NETO, M. S. de. Degradação ambiental nas vertentes norte da bacia hidrográfica rio Jaguaribe - Conceição do Almeida - Bahia In: SIMPÓSIO BRASILEIRO DE GEOGRAFIA FÍSICA APLICADA, 12., 2007(b). Anais. Natal, UFRN, 2007. CD-ROM.

MONTEIRO, C. A. F. Derivações antropogênicas dos Geossistemas terrestres Santos, A. M. dos; Galvíncio, J. D. Moura, M S. B. de. perspectivas urbanas e agrárias ao problema da elaboração de modelos de avaliação. R. RA'EGA, Curitiba, 5:197-226, 2001.

NETO, D. J. de S. VILLA GÓIS, D. Análise Comparativa dos Impactos ambientais nas barragens do Rio da Dona - Santo Antônio de Jesus-BA. In: SIMPÓSIO BRASILEIRO DE GEOGRAFIA FÍSICA APLICADA, 12., 2007. Anais. Natal, UFRN, 2007. CDROM.

NIMER, E. Pluviometria e recursos hídricos de Pernambuco e Paraíba. Rio de Janeiro: IBGE, 1979. 117p.

SUPERINTENDÊNCIA do Desenvolvimento do Nordeste - SUDENE. Dados Pluviométricos Mensais do Nordeste. Recife: Grupo de Trabalho de Hidrometeorologia, 1990. 363 p.

TORRES, A. B. Distribuição pluviométrica sobre a bacia hidrográfica do rio Doce- MG. In: SIMPÓSIO BRASILEIRO DE GEOGRAFIA FÍSICA APLICADA, 12., 2007. Anais. Natal, UFRN, 2007. CD-ROM.

TUCCI, C. E. M. Regionalização de vazões. In: TUCCI, C. E. M., ed. Hidrologia: ciência e aplicação. 2ed. Porto Alegre: EDUFRGS:ABRH, 2000. p. 573-611. 


\section{RBGF - Revista Brasileira de Geografia Física \\ Recife-PE Vol. 01 n.01 Mai/Ago 2008, 14-27}

Tabela 01: dados pluviométricos observados no posto B. Fogo-Igarassu.

\begin{tabular}{llll}
\hline Posto: P1 & Latitude: $-7^{\circ} 45^{\prime} 47^{\prime \prime}$ & Longitude: $-35^{\circ}{ }^{\prime}{ }^{\prime} 16^{\prime \prime}$ & Altitude: $118 \mathrm{~m}$ \\
\hline Anos & $\begin{array}{l}\text { Pluviosidade anual } \\
\text { total }(\mathrm{mm})\end{array}$ & Anos & $\begin{array}{l}\text { Pluviosidade anual } \\
\text { total }(\mathrm{mm})\end{array}$ \\
\hline 1965 & 1371,1 & 1979 & 1532 \\
1966 & 1902,9 & 1980 & 999,9 \\
1969 & 1481,6 & 1981 & 862,6 \\
1970 & 1504,5 & 1982 & 889,9 \\
1971 & 1217,4 & 1983 & 952 \\
1972 & 1316,7 & 1984 & 757,2 \\
1974 & 1997,7 & 1985 & 1101,7 \\
1975 & 1197,1 & 1986 & 1163,2 \\
1976 & 1078,4 & 1988 & 709,4 \\
1978 & 1324,8 & & \\
Média da série histórica:1536,24 mm & & \\
\hline
\end{tabular}

Tabela 02: dados pluviométricos observados no posto Machados.

\begin{tabular}{llll}
\hline Posto: P2 & Latitude: $-7^{\circ} 42^{\prime} 344^{\prime \prime}$ & Longitude:-35'29’49,5” & Altitude: $350 \mathrm{~m}$ \\
\hline Anos & $\begin{array}{l}\text { Pluviosidade anual } \\
\text { total (mm) }\end{array}$ & Anos & $\begin{array}{l}\text { Pluviosidade anual } \\
\text { total (mm) }\end{array}$ \\
\hline 1965 & 690,2 & 1979 & 1222,1 \\
1966 & 1070,2 & 1980 & 998,1 \\
1969 & 1442,5 & 1981 & 1046,8 \\
1970 & 1208,8 & 1982 & 1163,7 \\
1971 & 1277 & 1983 & 906,1 \\
1972 & 1312,5 & 1984 & 1464,6 \\
1974 & 1601,7 & 1985 & 1559,3 \\
1975 & 1307,2 & 1986 & 1780,3 \\
1976 & 1179,5 & 1988 & 1231,6 \\
1978 & 1610,5 & & \\
& & & \\
Média da série histórica: $1266,98 \mathrm{~mm}$ & & \\
\hline
\end{tabular}

Tabela 03: dados pluviométricos observados no posto Timbauba.

\begin{tabular}{|c|c|c|c|}
\hline Posto:P3 & Latitude:-7³0'29”' & Longitude: $-35^{\circ} 16^{\prime} 40^{\prime \prime}$ & Altitude: $250 \mathrm{~m}$ \\
\hline Anos & $\begin{array}{l}\text { Pluviosidade anual } \\
(\mathrm{mm})\end{array}$ & Anos & $\begin{array}{l}\text { Pluviosidade total } \\
\text { anual (mm) }\end{array}$ \\
\hline 1965 & 1137 & 1979 & 1044,2 \\
\hline 1966 & 1129,6 & 1980 & 1078,4 \\
\hline 1969 & 1177,4 & 1981 & 1014,2 \\
\hline 1970 & 1236,9 & 1982 & 1172,6 \\
\hline 1971 & 1311,7 & 1983 & 1096,1 \\
\hline 1972 & 1051,8 & 1984 & 1275,2 \\
\hline 1974 & 1105,8 & 1985 & 1840,6 \\
\hline 1975 & 990,1 & 1986 & 2262,9 \\
\hline 1976 & 1103,7 & 1988 & 1477,4 \\
\hline 1978 & 2109,4 & & \\
\hline
\end{tabular}

Santos, A. M. dos; Galvíncio, J. D. Moura, M S. B. de. 
Média da série histórica: 1295,52 mm

Tabela 04: dados pluviométricos observados no posto Bom Jardim.

\begin{tabular}{l|l|l|l|}
\hline Posto: P4 & Latitude: $-7^{\circ} 48^{\prime} 24,8^{\prime \prime}$ & Longitude: $-35^{\circ} 34^{\prime} 50^{\prime \prime}$ & Altitude: $300 \mathrm{~m}$ \\
\hline Anos & $\begin{array}{l}\text { Pluviosidade anual } \\
\text { total }(\mathrm{mm})\end{array}$ & Anos & $\begin{array}{l}\text { Pluviosidade total } \\
\text { anual (mm) }\end{array}$ \\
\hline 1965 & 1027,5 & 1979 & 1532 \\
1966 & 1470,4 & 1980 & 999,9 \\
1969 & 770,6 & 1981 & 862,6 \\
1970 & 1174,5 & 1982 & 889,9 \\
1971 & 1163,2 & 1983 & 952 \\
1972 & 867,9 & 1984 & 757,2 \\
1974 & 926,3 & 1985 & 1101,7 \\
1975 & 1197,1 & 1986 & 1163,2 \\
1976 & 1078,4 & 1988 & 709,4 \\
1978 & 1324,8 & & \\
Média da série histórica: $1050,97 \mathrm{~mm}$ & &
\end{tabular}

Tabela 05: dados pluviométricos observados no posto Vicência.

\begin{tabular}{llll}
\hline Posto: P5 & Latitude:-7 37’35,8” & Longitude:-35'20’22,2” & Altitude: $290 \mathrm{~m}$ \\
\hline Anos & $\begin{array}{l}\text { Pluviosidade anual } \\
\text { total (mm) }\end{array}$ & Anos & $\begin{array}{l}\text { Pluviosidade anual } \\
\text { total (mm) }\end{array}$ \\
\hline 1965 & 1126,6 & 1979 & 1257,8 \\
1966 & 1411,5 & 1980 & 1015,8 \\
1969 & 687,3 & 1981 & 893,6 \\
1970 & 1194,8 & 1982 & 1236,9 \\
1971 & 746,8 & 1983 & 1121 \\
1972 & 1309,4 & 1984 & 1311,6 \\
1974 & 1625,2 & 1985 & 1309 \\
1975 & 1452,2 & 1986 & 1755,2 \\
1976 & 1292,6 & 1988 & 1278,2 \\
1978 & 1679,8 & & \\
Média da série histórica: $1253,88 \mathrm{~mm}$ & & \\
\hline
\end{tabular}

Tabela 06: dados pluviométricos observados no posto Aliança.

\begin{tabular}{llll}
\hline Posto: P6 & Latitude: $-35^{\circ} 13^{\prime} 48^{\prime \prime}$ & Longitude:-7³6’26,5” & Altitude: $158 \mathrm{~m}$ \\
\hline Anos & $\begin{array}{l}\text { Pluviosidade anual } \\
\text { total }(\mathrm{mm})\end{array}$ & Anos & $\begin{array}{l}\text { Pluviosidade anual } \\
\text { total (mm) }\end{array}$ \\
\hline 1965 & 902 & 1979 & 828,9 \\
1966 & 1112,2 & 1980 & 715 \\
1969 & 853,1 & 1981 & 1028,8 \\
1970 & 1116,2 & 1982 & 1833,4 \\
1971 & 823,2 & 1983 & 1512,2 \\
1972 & 576,6 & 1984 & 1253,9 \\
1974 & 1020,2 & 1985 & 598,3 \\
1975 & 913,2 & 1986 & 1319,2
\end{tabular}

Santos, A. M. dos; Galvíncio, J. D. Moura, M S. B. de. 


\section{RBGF - Revista Brasileira de Geografia Física}

Recife-PE Vol. 01 n.01 Mai/Ago 2008, 14-27

1976

1263,4

1988

Média da série histórica: 1067,36 mm

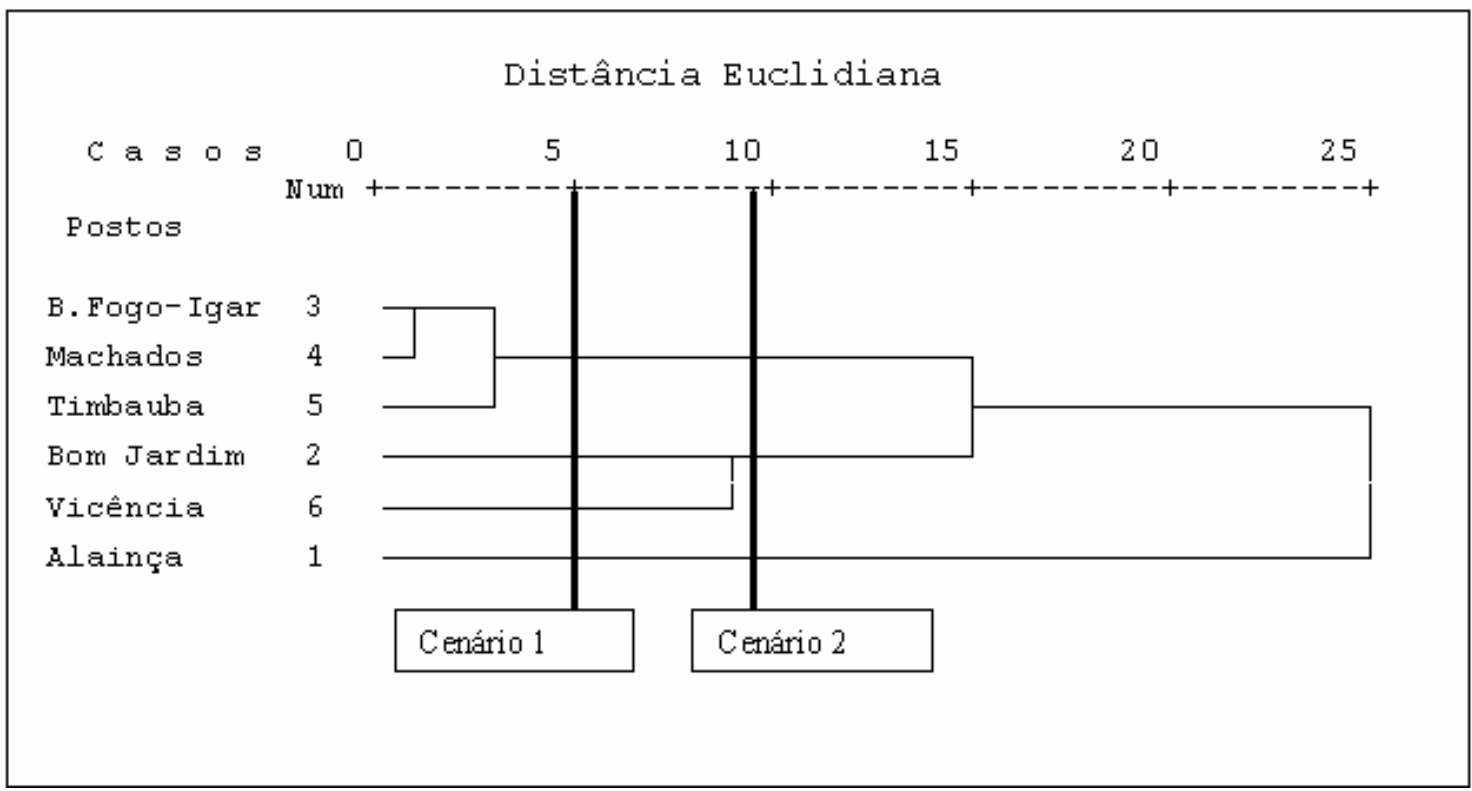

Figura 03: Dendograma dos postos pluviométricos da bacia hidrográfica do rio Goiana-PE gerado pelo método de agrupamento de Ward. 